\title{
Efeito pós-barragem nos municípios impactados por usinas hidrelétricas no estado do Tocantins/Brasil
}

O objetivo deste artigo é analisar os efeitos pós-barragem da instalação de Usinas hidrelétricas nos municípios do Estado do Tocantins e a contribuição no desenvolvimento local propagado por esses empreendimentos. Como metodologia foi analisado o índice de desenvolvimento regional (IDR) e as variáveis econômicas: Imposto sobre circulação de mercadoria e serviços (ICMS), Produto Interno Bruto (PIB) e número de empregos. Os principais resultados apontam que mesmo havendo uma melhoria do IDR, os efeitos positivos das barragens foram pontuais e em períodos específicos da construção, observados pelo comportamento das variáveis nos anos antes e depois dos empreendimentos. Essa observação nos permitiu fazer uma analogia com a teoria econômica do boomcolapso (boom and bust), que demonstra um alto índice de crescimento no período de implementação que depois não se mantém. As conclusões apontam que a promessa de desenvolvimento local propagada na aprovação do empreendimento, não se consolidou nas localidades pesquisadas. Podem ter ocorrido benefícios a nível nacional atendendo a necessidade de expansão energética, no entanto, não ficou demonstrado impactos positivos em nível local, além disso, as implicações ambientais e sociais podem ser maiores do que o retorno alcançado.

\section{Post-dam effect in the municipalities impacted by hydroeletric plants in the state of Tocantins/Brazil}

\begin{abstract}
The objective of this article is to analyze the post-dam effects of the installation of hydroeletric plants in the municipalities of the State of Tocantins and the contribution in the local development propagated by these enterprises. As methodoly the regional development index (IDR) and the economic variables were analyzed: Tax on the circulation of merchandise and services (ICMS), gross domestic product (GDP) and number of jobs. The main results indicate that though there is an improvement in the IDR, the positive effects of the dams were punctual and at specific periods of construction, observed by the behavior of the variables in the years before and after the projects. This observation allowed us to make an analogy with the economic theory of boom and bust, which shows a high growth rate in the period of implementation and then does not hold. The conclusions indicate that the promises of local development propagated in the approval of the enterprise, was not consolidated in the localities surveyed. There may have been benefits at the national level in light of the need for energy expansion, however, no positive impacts have been demonstrated at the local level, moreover, the environmental and social implications may be greater than return achieved.
\end{abstract}

Keywords: Boom-bust; Post-dam; Economic variables; Local Development.

Topic: Desenvolvimento, Sustentabilidade e Meio Ambiente

Reviewed anonymously in the process of blind peer.
Received: 12/04/2019 Approved: 27/05/2019
Adila Maria Taveira de Lima (iD

Universidade Federal do Tocantins, Brasil http://lattes.cnpq.br/7969320948448461 http://orcid.org/0000-0002-0691-444X adm.adila@gmail.com

Robert John Buschbacher (iD)

Universidade da Flórida, Estados Unidos http://lattes.cnpq.br/5948282415581862 http://orcid.org/0000-0002-6727-3834

rbusch@ufl.edu

Nilton Marques de Oliveira (iD

Universidade Federal do Tocantins, Brasil http://lattes.cnpq.br/9714154982299224 http://orcid.org/0000-0001-6485-314X niltonmarques@uft.edu.br

\author{
Mac David da Silva Pinto (ib \\ Universidade Federal do Tocantins, Brasil \\ http://lattes.cnpq.br/3182243226951228 \\ http://orcid.org/0000-0003-3492-2567 \\ macdavid@uft.edu.br \\ Erisvaldo de Oliveira Alves (iD \\ Universidade Federal do Tocantins, Brasil \\ http://lattes.cnpq.br/1444539237263300 \\ http://orcid.org/0000-0002-7608-0858 \\ alvesbm12@gmail.com \\ Elineide Eugênio Marques (iD) \\ Universidade Federal do Tocantins, Brasil \\ http://lattes.cnpq.br/9875056556045599 \\ http://orcid.org/0000-0003-0223-6853 \\ emarques@uft.edu.br
}

Referencing this:

LIMA, A. M. T.; BUSCHBACHER, R. J.; OLIVEIRA, N. M.; PINTO, M. D. S.; ALVES, E. O.; MARQUES, E. E.. Efeito pós-barragem nos municípios impactados por usinas hidrelétricas no estado do Tocantins/Brasil. Revista Ibero Americana de Ciências Ambientais, v.10, n.3, p.138155, 2019. DOI: http://doi.org/10.6008/CBPC2179-

$\underline{6858.2019 .003 .0013}$ 


\section{INTRODUÇÃO}

Constantemente a implementação de projetos desenvolvimentistas são propagados como uma forma de promover o desenvolvimento local e melhoria da qualidade de vida na região. No entanto, as opiniões são divergentes uma vez que de um lado agentes governamentais e empreendedores afirmam que, além da necessidade de obras de infraestrutura para a política de desenvolvimento nacional, tais empreendimentos também são impulsionadores no desenvolvimento local. Por outro lado, agentes locais, pesquisadores, e especialmente os atingidos relatam que tal desenvolvimento não é proporcionado.

Dentre esses projetos considerados prioritários para o desenvolvimento do Brasil, as usinas hidrelétricas - intensificadas principalmente nos últimos vinte anos - têm sido motivo de muitos questionamentos nas localidades em que foram implementadas, sobretudo daquelas localizadas no território da Amazônia Legal, região até então pouco explorada por este setor. Os relatos destacam que muitas das promessas de desenvolvimento não se concretizaram. Mesmo a energia gerada é direcionada para os grandes centros.

Diegues (2005) destaca que os projetos pautados no progresso, inicialmente convencem, mas frequentemente os resultados divergem da proposta inicial não sendo significativos na região em que estão inseridos. Corroborando com essa questão Fenzl et al. (2000), Bermann (2012), Souza et al. (2015) e Fearnside (2017), enfatizam que o esperado desenvolvimento dos municípios não acontece, uma vez que a maior parte do aumento de geração de energia foi absorvida pelas indústrias de mineração ou por grandes centros industriais, e que o aumento do PIB local não reflete o crescimento do número de empregos e a melhoria na qualidade de vida da população. Garcia et al. (2008), complementam afirmando que o planejamento nacional, sempre esteve priorizando o crescimento de grandes centros e não o desenvolvimento social e ambiental da região onde se constroem esses empreendimentos, apesar de muitas vezes o discurso ser focado em benefícios que a localidade receberá.

Gomes (2014) destaca que por ocasião do planejamento da expansão do setor elétrico, o discurso do governo e os documentos técnicos ressaltam que a implantação desses empreendimentos se configura também como uma fonte indutora de desenvolvimento local, embora não existam evidências empíricas claras sobre esta relação. E afirma que "mesmo sem evidências científicas desta relação, esse discurso do desenvolvimento local tem sido utilizado para justificar a construção de novos empreendimentos e justificam ainda os impactos negativos invariavelmente deflagrados nos territórios onde tais empreendimentos são instalados" (GOMES, 2014).

A exemplo da afirmação de Gomes (2014) da propagação de desenvolvimento local nos estudos e documentos técnicos, destaca-se os Estudos de Impacto Ambiental (EIA) para a UHE São Salvador, no Rio Tocantins, que ressalta "além da geração de energia elétrica ser, um dos grandes impulsionadores do desenvolvimento econômico, proporcionando um aquecimento dos serviços públicos e privados, a UHE São Salvador auxiliará no atendimento à demanda existente no mercado de forma a colaborar para diminuir esse 
déficit e aumentar, de imediato, as possibilidades de desenvolvimento regional" (EIA-RIMA São Salvador ${ }^{1}$ ). No mesmo sentido para a UHE de Estreito, também no rio Tocantins, ainda na fase de estudos de viabilidade, a justificativa também é pautada no mesmo argumento: “As alternativas para a condução do desenvolvimento e modernização da região que vêm sendo adotadas se apresentam associadas às parcerias entre os setores público e privado, como a ampliação da infraestrutura viária e obras de geração e distribuição de energia elétrica, suporte fundamental para inserção de sua economia no contexto macro regional (CNEC, 2001).

No entanto, esse impulsionamento na economia local, pode ser passageiro, ocasionando um grande crescimento desordenado, na fase de implantação desses empreendimentos e, logo depois, o decrescimento acontece com a finalização da obra, dessa forma o desenvolvimento propagado é por período determinado. Segundo Rothman (2008) esse modelo não prioriza e nem garante o desenvolvimento local onde são construídas as hidrelétricas. Nem mesmo o acesso à energia elétrica às populações rurais mais pobres e distantes é consolidado.

É fato que com a chegada da construção de um empreendimento, especialmente nos pequenos municípios atingidos, ocorre uma espécie de boom, em consequência dessa obra. Cresce o número de habitantes, com os trabalhadores da obra civil, consequentemente as movimentações econômicas e sociais, gerando demanda para serviços e ampliando a rede de atendimento para aquela demanda. Há investimentos na infraestrutura de atendimento de serviços básicos, desde a saúde, educação e serviço social do município. No entanto, frequentemente, depois que finaliza a construção, os municípios sofrem um esvaziamento de trabalhadores e investidores, um bust (colapso), podendo voltar ao estágio inicial, ou seja, uma dinâmica social e econômica é alterada em curto espaço de tempo. Dessa forma, questiona-se a efetividade das contribuições desses empreendimentos projetados como 'desenvolvimentista' ao desenvolvimento local.

Diante desse contexto, buscou-se nessa pesquisa, analisar os municípios diretamente atingidos pela implementação de projetos hidrelétricos, no Estado do Tocantins, determinando como questões norteadoras: (i) Pode-se atribuir desenvolvimento local em decorrência da implementação grandes projetos de infraestrutura (hidrelétricas) nos municípios diretamente impactados? (ii) As variáveis econômicas desses municípios tiveram crescimento contínuo ao longo do tempo, ou ocorreu o fenômeno de boom and bust?

Portanto, estruturou-se esse artigo com essa breve introdução do tema e problemática abordada e das questões a que se busca responder, seguido de um aporte teórico com a explanação dos conceitos base para discussão. Na sequência, descreveu-se os aspectos metodológicos e área de estudo, dando continuidade com a exposição de resultados e discussão, e por fim as considerações finais.

\section{REVISÃO TEÓRICA}

\section{Política energética brasileira e o caso das hidrelétricas}

O setor hidrelétrico no Brasil teve uma ampliação, especialmente a partir da década de 1970, com o

\footnotetext{
${ }^{1}$ http://licenciamento.ibama.gov.br/Hidreletricas/Sao\%20Salvador/VOLUME_I/878800-6B-RL-0001-0-ParteA-CapII.pdf
} 
início das construções de grandes hidrelétricas, como Sobradinho, Itaparica, Itaipu ${ }^{2}$ e Tucuruí ${ }^{3}$, na época, consideradas prioritárias para a sustentação do país e um grande salto na geração de energia. Mas no final da década de 1980, com a necessidade de ampliação da matriz energética, começaram as discussões sobre a privatização do setor elétrico. Em 1994, o setor elétrico inicia uma nova fase, com a transferência de ativos do Estado para a iniciativa privada e predomínio do 'estado regulador' sobre o 'estado investidor' (ANEEL, 2008).

Após o estabelecimento da nova regulação para o setor, inicia-se um novo ciclo de construções hidrelétricas, e assim, projetos, até então, criticados pela opinião pública nacional e internacional em defesa da população atingida, dos povos indígenas e do meio ambiente, foram reavaliados e autorizados sua implementação. Projetos polêmicos como, o complexo do Rio Madeira - Hidrelétricas de Jirau e Santo Antônio (RO), Belo Monte, no rio Xingu (PA), Lajeado no Rio Tocantins (TO) e Estreito no Rio Tocantins (MA), dentre outros, foram construídos, considerando as implicações ambientais e sociais estabelecidas como obrigação nos estudos de impacto ambiental, mas negligenciadas ao longo do processo de licenciamento, restando conflitos até os dias atuais (LIMA, 2013).

Dentre as bacias amazônicas, a do Rio Tocantins é aquela que possui o maior número de empreendimentos hidrelétricos construídos. Do total de grandes empreendimentos previstos no Plano Decenal de Expansão de Energia 2021 (BRASIL, 2012), a maioria já está em operação, que são as hidrelétricas de Serra da Mesa, Cana Brava, São Salvador, Peixe Angical, Lajeado e Estreito. Os demais empreendimentos previstos no Plano estão em diferentes fases do processo de licenciamento (Serra Quebrada, Tupiratins, Marabá) ou suspenso devido a questões levantadas durante o licenciamento, como é o caso de Ipueiras, também no Estado do Tocantins (LIMA, 2013).

Estudos relatam que os impactos ambientais com efeito cumulativo não são considerados em nível de bacia, e que possivelmente um rio a exemplo do rio Tocantins, com inúmeras barragens, se torna um rio sem atividade originária. Além disso, como agravante, as hidrelétricas passaram a fazer parte de grupos internacionais, que passam a controlar um bem público, o rio, e sua operacionalização. Nesta visão, Benincá (2011) acrescenta que o modelo estatal de energia promoveu a ocupação injusta e agressiva de territórios, gerando sérios impactos ambientais e destaca que nesses processos, são praticadas graves agressões culturais e físicas contra populações tradicionais; amplia-se o êxodo rural, com suas políticas de indenizações insuficientes a manter as pessoas no campo, vindo a contribuir com o aumento das periferias da cidade.

Para Rothman (2008), a sociedade deve atentar para essa estratégia que prioriza a aceleração na construção de barragens hidrelétricas, sem respeitar a legislação sobre licenciamento ambiental e os regulamentos procedimentais pertinentes para garantir esses direitos, para que não venham desencadear

\footnotetext{
${ }^{2}$ Hidrelétrica binacional situada no rio Paraná, responsável por aproximadamente $25 \%$ de toda energia elétrica consumida no Brasil. As obras civis tiveram início em janeiro de 1975 e a usina entrou em operação comercial em maio de 1984. A última unidade geradora entrou em operação em abril de 1991.

${ }^{3}$ A Usina Hidrelétrica de Tucuruí está localizada no Rio Tocantins, no município de Tucuruí, no estado do Pará. É a primeira grande usina da Amazônia. Com capacidade inicial de geração de $4.245 \mathrm{MW}$ nas 12 turbinas. Sua construção teve início em 1974, inaugurada em 1984 . Em 1998 foi iniciada a ampliação da hidrelétrica e a instalação de mais 12 máquinas, o que permitiu a expansão da potência em mais 4.125 MW. A capacidade atual da usina é de $8.370 \mathrm{MW}$ (ANEEL, 2008).
} 
uma trágica repetição dos desastrosos impactos sociais e ambientais do passado já registrados em outras localidades.

A critica a política energética brasileira se faz, sobretudo à maneira como o processo vem sendo conduzido e operacionalizado. As questões relacionadas a necessidade de ampliação da matriz elétrica não serão abordadas nesse trabalho, ainda que se observa em estudos recentes, outras fontes de energia adotadas por outros países, mais viáveis e menos impactante que a energia hidráulica.

\section{Grandes projetos de desenvolvimento e impactos locais: economia de boom and bust}

A história econômica mundial mostra claramente o quanto o 'desenvolvimento' não se processou de forma especialmente homogênea, em função dos modelos mundialmente adotados de reprodução de capital que, ainda hoje, têm papel altamente segregado, pois, cotidianamente ocorre a priorização de algumas áreas para implementação de projetos desenvolvimentistas, em detrimento de outras (OLIVEIRA, 2003).

Essas propostas de desenvolvimento, tem quase sempre, a mesma justificativa: necessidade de infraestrutura para o desenvolvimento do país, proporcionar o desenvolvimento local, impulsionar o progresso na região, gerar emprego e melhorar a qualidade de vida da população. No entanto, pode ser que essas promessas não se traduzam em realidade nas localidades. A imagem de crescimento, investimentos, geração de valor pode ser súbita, momentânea, desequilibrada e sem continuidade, uma vez que foram ocasionadas por demandas externas, envolvendo processos impositivos e não amadurecidos para a comunidade local.

Pode-se fazer uma analogia desse fenômeno com a teoria econômica do boom and bust ${ }^{4}$, da escola austríaca, fundamentada em ciclos econômicos, que se estrutura basicamente em estimular o crédito e a consequente atividade econômica, gerando aquecimento da economia, criando uma falsa 'bolha' (boom) de crescimento. No entanto, Harris (2013), destaca que os defensores desse modelo esquecem que mesmo que ele possa superar dificuldades momentâneas, ele produzirá um efeito que pode ser bem pior num futuro próximo, quando a 'falsa ideia' de crescimento cair. Isso porque após esse boom, não ordenado e induzido, gera um posterior desequilíbrio, ao retirar a injeção de recursos externos, chamado de bust (colapso) estagnando ou gerando decrescimento no mercado novamente.

Em analogia a essa teoria econômica, pode-se atribuir características similares, de boom and bust, para os processos de construção de grandes obras de infraestrutura e, especialmente, o caso das construções de hidrelétricas, ocorre um boom, quando das movimentações para a construção do empreendimento chegam aos pequenos locais. A partir daí cria-se uma expectativa, fazem-se investimentos em novos negócios e serviços públicos, devido ao aumento da população e especulação de renda pelos empregos gerados, e ocorre maior circulação de capital na localidade.

\footnotetext{
${ }^{4}$ Teoria econômica da escola austríaca, inicialmente apresentada por Ludwig Von Mises, baseada nas ideias preliminares de Carl Menger e BöhmBawerk. Posteriormente a teoria foi desenvolvida por Friedrich Hayek. Essa teoria tem como objetivo explicar os ciclos econômicos como consequência do crescimento excessivo de crédito por conta de políticas monetárias de fomento econômico que fazem com que as taxas de juros fiquem muito baixas por um longo período de tempo, criando bolhas advindas de excesso de crédito e diminuição da poupança (BERTELLI, 2011).
} 
A empresa construtora movimenta economicamente a cidade, uma vez que há uma injeção de recursos por meio de circulação de capital e serviços. No entanto, passando o 'boom' da construção daquele projeto, volta para uma situação de estagnação, com o esvaziamento dos trabalhadores e da circulação de renda local, gerando um colapso econômico ou bust. Além disso, se somam ao bust econômico, as consequências sociais, as perdas ambientais advindas do empreendimento e as reclamações de medidas compensatórias e mitigatórias que por ventura, ocorrem de não serem atendidas em sua totalidade.

São obras com custos enormes, consequências ambientais e sociais seríssimas e que comumente deixam para os municípios, problemas judiciais, sociais, ambientais e econômicos (GARCIA et al., 2008); BERMANN, 2012). Se, antes, foi criada uma estrutura para a fase de implantação da obra, depois, com o rápido desmonte da fase de construção, configura uma necessidade de nova readequação. Isso pode comprometer a governança do município, com uma ideia ilusória de desenvolvimento, que embora possa ter obtido um aumento na arrecadação do Imposto sobre Circulação de Mercadorias e Serviços - ICMS (com a geração de energia), por exemplo, adquirem inúmeros problemas para serem sanados com essa receita, que nem sempre se transforma em serviços de melhor qualidade para a população.

De acordo com Celentano et al. (2007), o modelo de ocupação predominante, sobretudo na região amazônica, tende a resultar em uma economia local que segue esse padrão 'boom-colapso'. Schneider et al. (2000) destacam que é comum nos primeiros anos da atividade econômica ocorrer um rápido e efêmero crescimento (boom), seguido de um declínio significativo em renda, emprego e arrecadação de tributos (colapso). Ou seja, esse ciclo de desenvolvimento econômico, pode ter uma duração média de 5 anos, equivalente ao período médio em que se constroem um empreendimento de infraestrutura (pode ser mais ou menos, dependendo do projeto, prazo e outros fatores).

Após a finalização da construção, os empregos gerados não têm continuidade e não garantem a manutenção de renda e circulação de moeda no local, os pequenos negócios criados em função da obra perdem a clientela rapidamente e assim, entram em declínio. O investimento em serviços de assistência básica, antes necessário para atendimento desses trabalhadores e famílias, muitas vezes não tem como serem mantidos unicamente pelo poder municipal, comprometendo também a governança e sustentabilidade local.

Diante desse contexto, estudos e reflexões acerca dessas propostas de grandes projetos de desenvolvimento, com impactos locais, considerando que a maioria dos municípios impactados são pequenos e pouco desenvolvidos, e comumente não tem diversificação de suas atividades econômicas, devem ser incrementados, para que possa ser evitado a repetição do modelo do boom and bust que vem ocorrendo, especialmente, na região amazônica, citado por Celentano et al. (2007).

\section{METODOLOGIA}

\section{Caracterização da área de estudo e das hidrelétricas estudas}

Essa pesquisa foi desenvolvida no Estado do Tocantins, nos municípios que foram impactados pelos 
quatro últimos grandes empreendimentos hidrelétricos, implementados nos últimos 20 anos ao longo do rio Tocantins (Figura 1). As Usinas Hidrelétricas (UHE) implementadas foram: Luís Eduardo Magalhães - Lajeado (2001)5; Peixe Angical (2006), São Salvador (2008) e Estreito (2010).
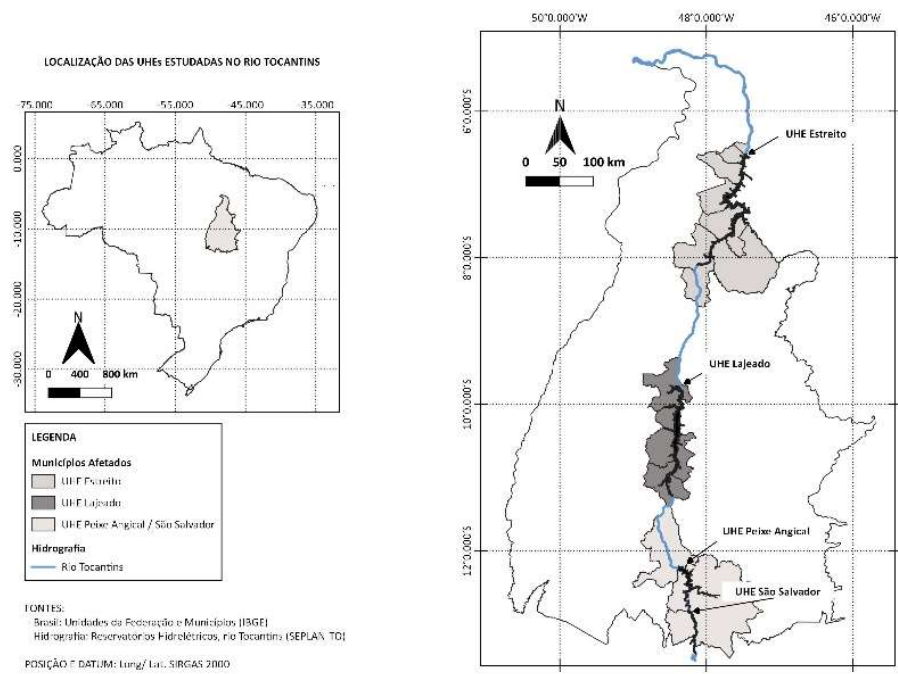

Figura 1: Localização das Usinas Hidrelétricas em operação, nos limites do Estado do Tocantins.

Destaca-se ainda algumas características das hidrelétricas pesquisadas, municípios atingidos e período de implementação, foco do estudo: A Hidrelétrica Luís Eduardo Magalhães - UHE Lajeado foi a primeira hidrelétrica do país construída pela iniciativa privada, após a reestruturação do setor elétrico na década de 1990. Tem uma potência instalada de 902,5 MW, sendo que a construção teve início em 1998 e a primeira turbina começou a gerar em 2001. A construção da barragem e a formação do reservatório atingiram cinco municípios do Estado do Tocantins: Miracema do Tocantins, Lajeado, Palmas, Porto Nacional, Brejinho de Nazaré e Ipueiras - inundando uma área de $630 \mathrm{~km}^{2}$.

A UHE de Peixe Angical tem um potencial de 452 MW e começou a ser construída em 2002, iniciando as operações em 2006. Está localizada entre os municípios de Peixe, São Salvador e Paranã, na região sul do Estado. A implementação dessa hidrelétrica formou um reservatório de 294 km², impactando diretamente esses três municípios.

A UHE São Salvador tem um potencial 243,2 MW e está localizada entre os municípios de São Salvador e Paranã, ambos na região sul do estado do Tocantins. Esta usina teve a construção iniciada em 2005 e começou a operar em 2008, com área de $104 \mathrm{~km}^{2}$ de reservatório, impactando diretamente no Estado do Tocantins, os municípios de Paranã, São Salvador e Palmeirópolis.

A UHE Estreito está localizada entre os estados do Maranhão e Tocantins e possui uma capacidade geradora de $1.087 \mathrm{MW}$, sendo o maior empreendimento dentre os quatro analisados. Sua construção teve início em 2006 e começou a operar em 2010. Impactou diretamente dez municípios no Estado do Tocantins: Aguiarnópolis; Babaçulândia; Barra do Ouro; Darcinópolis; Filadélfia; Goiatins; Itapiratins; Palmeirante; Palmeiras do Tocantins; Tupiratins, com uma área de $400 \mathrm{~km}^{2}$ de reservatório.

Os projetos hidrelétricos analisados atingiram diretamente municípios no Estado do Tocantins, Goiás

\footnotetext{
${ }^{5}$ Respectivamente, o ano em que a Usina Hidrelétrica entrou em operação (obra concluída).
} 
e Maranhão. No entanto, neste estudo foram considerados somente os efeitos nos municípios na área do Estado do Tocantins implicados pelas hidrelétricas referidas (Fig.1), por ter o maior número de municípios implicados diretamente e, também, visando padronizar o efeito da gestão estadual sobre os municípios.

Importante destacar que dentre os municípios atingidos por esses empreendimentos, optou-se excluir a capital Palmas, por se tratar da maior cidade do Estado, apresentando variáveis, diversidade de investimentos e população, muito diferentes dos demais municípios, que são menores, localizados no interior do Estado e que não tem grande diversificação de investimentos. Dessa forma, obteve-se uma amostra de 19 municípios (Figura 2).
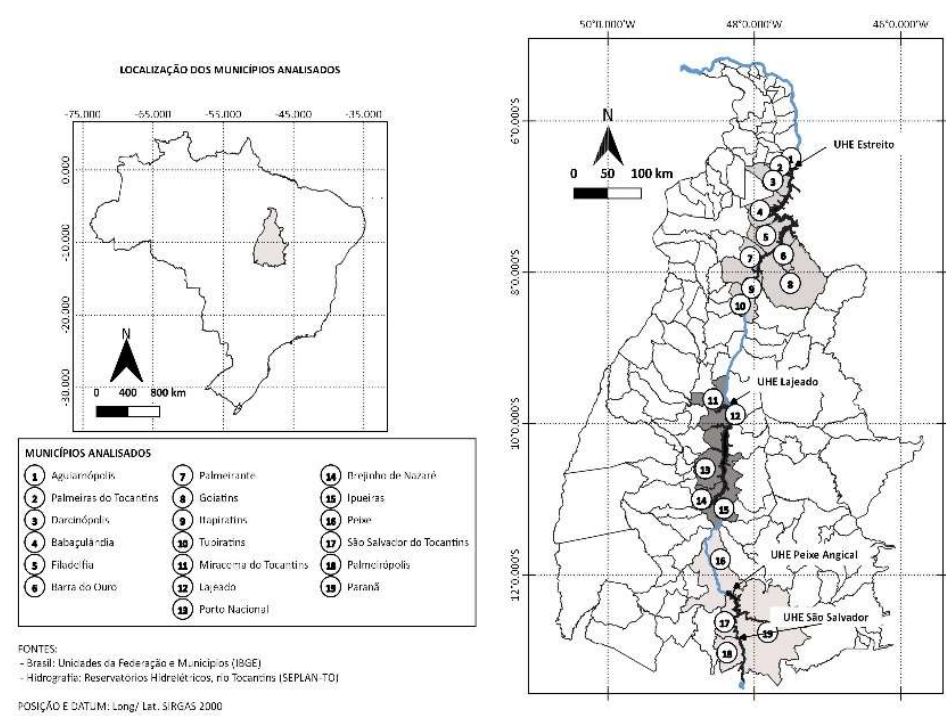

Figura 2: Municípios atingidos pelas hidrelétricas no Estado do Tocantins.

Destaca-se que os municípios de Paranã (2) e São Salvador do Tocantins (4), tiveram sobreposição de impactos, pois foram atingidas pela construção das hidrelétricas Peixe Angical e de São Salvador. O período de implantação dos empreendimentos foi delimitado com base na emissão das licenças ambientais (Quadro 1). Ressalta-se que a UHE Lajeado, que entrou em operação antes do período estudado, foi mantida nas análises buscando identificar o comportamento pós-barragem.

Quadro 1: Usinas Hidrelétricas e o período de licenciamento: prévio (LP), Instalação (LI) e operacional (LO).

\begin{tabular}{|l|l|l|l|}
\hline Usina hidrelétrica (UHE) & Licença Prévia & Licença de Instalação & Licença de Operação \\
\hline Lajeado & 1997 & 1998 & 2001 \\
\hline Peixe & 2001 & 2002 & 2006 \\
\hline São Salvador & 2004 & 2005 & 2008 \\
\hline Estreito & 2005 & 2006 & 2010 \\
\hline
\end{tabular}

\section{Fontes de dados e formas de análise}

Para análise dessa pesquisa, considerou-se o Índice de Desenvolvimento Regional (IDR), seguindo a metodologia proposta por Oliveira (2015), elaborado para os períodos de 1990, 2000 e 2010, para os municípios do Estado do Tocantins. Dessa forma buscou-se demonstrar a evolução do processo de desenvolvimento regional e a dinamicidade dos municípios, com intenção de comparar o antes e depois das hidrelétricas, analisando a conjuntura de sua evolução.

Além do IDR foram analisadas a evolução anual das variáveis econômicas: Imposto sobre Circulação 
de Mercadorias e Serviços (ICMS), Produto Interno Bruto (PIB) e geração e perda de empregos, no período de 2002 a 2016. Para a variável Produto Interno Bruto (PIB), foi estimada a contribuição percentual anual considerando os quatro setores componentes do PIB (Agropecuária, Indústria, Serviços e Imposto). Todas as variáveis selecionadas foram significativas para demonstrar um panorama dos efeitos das barragens nos municípios pesquisados e em que período e segmento tem variações mais acentuadas.

As variáveis econômicas foram coletadas nos bancos de dados de instituições oficiais, como Instituto Brasileiro de Geografia e Estatística - IBGE, Secretaria de Fazenda do Estado do Tocantins - SEFAZ, Secretaria de Planejamento do Estado do Tocantins - SEPLAN e Relação Anual de Informações Sociais - RAIS do Ministério do Trabalho e Emprego.

\section{RESULTADOS E DISCUSSÃO}

\section{Índice de Desenvolvimento Regional (IDR) para os Municípios Atingidos por Hidrelétricas}

De acordo com o trabalho de Oliveira (2015), a partir do cálculo dos indicadores sociais e econômicos, propostos pela metodologia, foram encontrados valores crescentes para o Índice de Desenvolvimento Regional, nos períodos de 1990, 2000 e 2010, para a maioria dos 19 municípios pesquisados (quadro 2):

Quadro 2: Índice de Desenvolvimento Regional (IDR) para os municípios pesquisados.

\begin{tabular}{|l|l|l|l|}
\hline Municípios & IDR 1990* & IDR 2000 & IDR 2010 \\
\hline Miracema do Tocantins & 0,213 & 0,186 & 0,172 \\
\hline Lajeado & - & 0,056 & 0,087 \\
\hline Porto Nacional & 0,283 & 0,223 & 0,196 \\
\hline Brejinho de Nazaré & 0,071 & 0,043 & 0,072 \\
\hline Ipueiras & - & 0,012 & 0,061 \\
\hline Peixe & 0,092 & 0,059 & 0,126 \\
\hline Paranã & 0,041 & 0,021 & 0,037 \\
\hline São Salvador & - & $-0,002$ & 0,040 \\
\hline Palmeirópolis & 0,157 & 0,087 & 0,084 \\
\hline Aguiarnópolis & - & 0,029 & 0,067 \\
\hline Babaçulândia & 0,022 & 0,025 & 0,058 \\
\hline Barra do Ouro & - & $-0,015$ & 0,025 \\
\hline Darcinópolis & - & 0,017 & 0,045 \\
\hline Filadélfia & 0,034 & 0,035 & 0,056 \\
\hline Goiatins & 0,047 & 0,014 & 0,043 \\
\hline Itapiratins & - & $-0,001$ & 0,039 \\
\hline Palmeirante & - & $-0,012$ & 0,014 \\
\hline Palmeiras do Tocantins & - & 0,003 & 0,049 \\
\hline Tupiratins & - & 0,005 & 0,060 \\
\hline
\end{tabular}

Fonte: Oliveira (2015). *Em 1990 alguns municípios ainda não haviam sido criados/emancipados, por isso não tinham dados independentes para o cálculo do IDR.

Segundo a classificação do IDR proposta por Oliveira (2015), em municípios polo, intermediários e retardatários, obtivemos de modo geral, uma evolução no período de 2000 e 2010, com o aumento daqueles classificados como intermediários e polos e redução no quantitativo de municípios retardatários (Quadro 3).

Quadro 3: Classificação dos municípios de acordo com o IDR.

\begin{tabular}{|l|l|l|}
\hline Classificação (base econômica) & 2000 & 2010 \\
\hline Polos (1,00-0,1) & 2 & 3 \\
\hline Intermediários (0,09-0,05) & 3 & 8 \\
\hline Retardatários (abaixo de 0,05) & 14 & 8 \\
\hline Total de municípios & 19 & 19 \\
\hline
\end{tabular}


A classificação do IDR mostra a evolução ocorrida no período entre os anos de 2000 e 2010, para os municípios pesquisados. Dentre os municípios impactados por hidrelétricas, haviam 14 em situação de retardatários, e no ano 2010, esse número reduziu para 8. Isso demonstra uma evolução no desenvolvimento na maioria dos municípios pesquisadas.

No entanto, a mesma tendência é demonstrada em outros municípios que não, necessariamente, abrigam projetos hidrelétricos. Oliveira (2015) analisou o IDR em todos os municípios tocantinenses (79 na época) e concluiu que em 1990, eram 16 municípios polos, 21 intermediários e 42 considerados retardatários. Em 2000, já com 139 municípios, foram 15 municípios polos, 34 intermediários e 90 retardatários. Em 2010, constatou-se uma melhora sensível do IDR, visto que, 16 foram classificados como polo, 82 intermediários e 41 retardatários. Ou seja, dos 90 municípios considerados retardatários, em 2000, em 2010 passaram 41, o que demonstra uma tendência de desenvolvimento do Estado como um todo (OLIVEIRA, 2015).

A discussão permeia entre a implementação dos grandes projetos desenvolvimentistas, no caso, as hidrelétricas, que contribuem para o desenvolvimento local. Apesar de verificar pelo IDR que há uma melhoria nos municípios de um modo geral, incluindo aqueles que também foram impactados por hidrelétricas, não se pode atribuir desenvolvimento especificamente a este tipo de empreendimento, uma vez que, como verificado, na maioria dos municípios do Estado do Tocantins houve o aumento desse indicador, no entanto, ocorreu também algumas exceções em alguns municípios apesar da melhoria da classificação.

Identificou-se que mesmo com a redução do número de municípios classificados como retardatários, alguns apresentaram valores abaixo do IDR inicial (2000), principalmente os que foram atingidos pela UHE lajeado. Nesse caso, os municípios de Miracema do Tocantins, Lajeado, Porto Nacional e Brejinho de Nazaré, apresentaram valores maior em 1990 do que 2000 e 2010, ou seja, esse período coincide com a finalização da obra da UHE e essas cidades tiveram um bust no IDR.

De um modo geral, o IDR é calculado a partir de variáveis obtidas no censo, como por exemplo do IBGE, que tem coleta decenal. Embora seja de suma importância para a avaliação do desenvolvimento municipal a médio prazo, pode ocultar a oscilação econômica (boom and bust) em curto prazo, causado por grandes empreendimentos. Na implantação de hidrelétricas, o processo desde o início até a inauguração, tem duração em torno de 4 a 5 anos, assim esses dados podem mascarar as contribuições ou danos causados na localidade e aquelas que foram prejudicadas ou beneficiadas.

Ainda assim, tivemos notórios resultados de boom and bust, nas principais cidades atingidas, especialmente as impactadas pela UHE Lajeado (Miracema do Tocantins, Lajeado, Porto Nacional e Brejinho de Nazaré) e as cidades atingidas em duplicidade por duas hidrelétricas: Peixe Angical e São Salvador, que neste caso, impactaram Paranã e Palmeirópolis. As demais apresentaram crescimento seguindo a tendência do Estado. 


\section{Análise da Evolução Anual das Variáveis Econômicas para os Municípios Tocantinenses: Identificando o período de Boom and Bust}

As variáveis econômicas analisadas (emprego, ICMS e PIB), contribuem para o entendimento da dinâmica ocorrida nos municípios. A partir desses dados foi possível verificar o cenário anual, identificando o movimento durante todo o processo de implementação e operação no pós-barragem. A geração de emprego, uma das variáveis com maior peso no cálculo do IDR, é um determinante na geração de renda dos municípios. Analisando os dados do saldo de emprego (empregos gerados e perdidos), de 2002 a 2016 , nos municípios diretamente atingidos, observa-se uma tendência de aumento e queda num curto período de tempo.

O ICMS é um balizador para repasses financeiros e da capacidade de arrecadação do município, que nos casos estudados, aumentou com a hidrelétrica, que assim como o IDR, é uma tendência identificada no Estado, com outros fatores econômicos atribuídos. O PIB decomposto é uma variável também muito importante, uma vez que nos permite não só averiguar o que o município produziu no geral, mas de forma decomposta, pode nos dá possibilidades de atribuir crescimento econômico, por setor. Dessa forma, podemos concluir se o desenvolvimento foi causado por indústrias, que podem estar agregadas ao setor elétrico, e atribuído uma consequência do empreendimento instalado, ou por setores já estabelecidos no Estado, como por exemplo, o setor agropecuário, que independe da UHE. Dessa forma, os resultados das variáveis econômicas foram organizados por grupo de municípios que foram atingidos por cada UHE.

\section{Análise das variáveis econômicas nos municípios tocantinenses impactados pela UHE Lajeado}

Para a UHE Lajeado, na análise do período proposto, foi possível identificar apenas o período pósbarragem, uma vez que analisamos os dados a partir de 2002 e esta usina teve sua construção iniciada em 1998, a partir deste ano e os subsequentes até sua finalização (2001), pode ter ocorrido o boom, na implementação do empreendimento, no entanto foi identificado o bust, tanto na análise do IDR, que nos períodos 2000 e 2010, demonstraram redução do indicador, como pelas variáveis econômicas verificadas no período pós-barragem (a partir de 2002).

Nota-se que a partir de 2002 houve uma estagnação dos municípios e, em especial do município de Lajeado, que foi sede da concentração da obra. Pode-se observar que com relação ao saldo de emprego nesses municípios implicados por essa usina, houve queda a quase zero na oferta de vagas (Fig. 3). Embora o impacto direto pela formação do reservatório (lago) tenha afetado quatro municípios (Ipueiras, Brejinho de Nazaré, Porto Nacional e Palmas), o impacto na geração de emprego foi percebido nos municípios de Miracema do Tocantins e Lajeado (onde se concentraram as obras) (Fig.3). No início da operação da UHE Lajeado (2002) o município de Miracema do Tocantins perdeu 1186 postos de trabalho sem que houvesse recuperação dos mesmos nos anos subsequentes (Fig. 3). Essa queda no emprego é bem evidenciada no gráfico que se inicia com valores negativos (fig. 3).

A UHE contribui com a arrecadação do ICMS de Miracema do Tocantins e Lajeado (fig. 3), no entanto, esse empreendimento não foi o determinante para o desenvolvimento local, uma vez que outros municípios, 
que não tiveram hidrelétricas, também tiveram aumento das variáveis econômicas, o que mostra uma tendência em todo o Estado, seja por fatores ligados a outros empreendimentos, seja por investimentos agropecuários, que é uma base econômica muito forte no Estado.
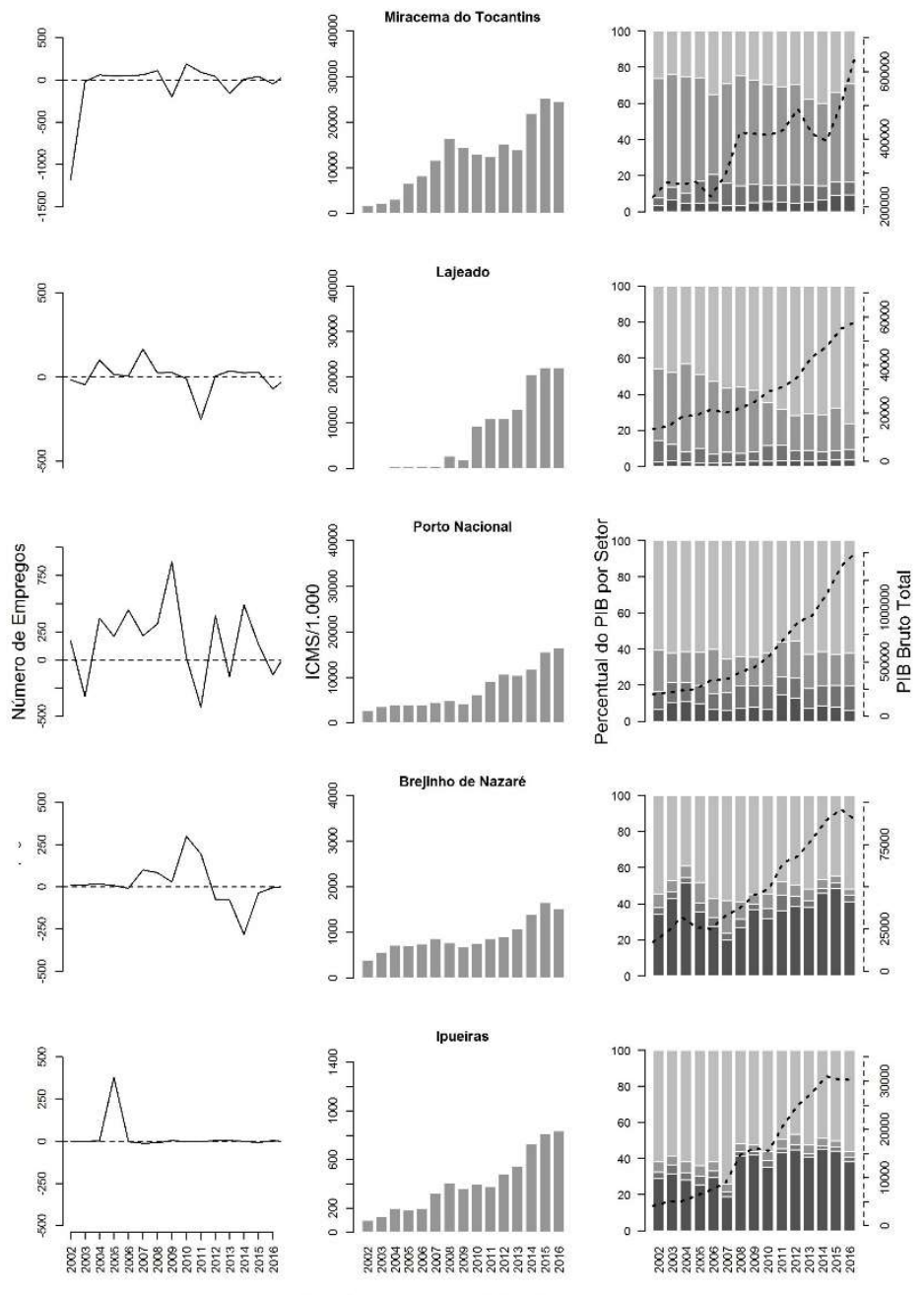

Figura 3: Variação dos Empregos gerados, da arrecadação de ICMS e PIB nos municípios impactados diretamente pela UHE Lajeado.

Análise das variáveis econômicas nos municípios tocantinenses impactados pelas UHEs Peixe Angical e São Salvador

Como esses empreendimentos estão muito próximos geograficamente, e houve sobreposição de impactos em dois municípios (Paranã e Palmeirópolis) por essas duas hidrelétricas, optou-se por analisar os resultados das variáveis econômicas no mesmo tópico e na mesma figura (fig. 4). Nos municípios de Peixe e Paranã (Figura 4) impactados pela hidrelétrica de Peixe Angical, viu-se que a variável 'emprego' teve um boom nos anos de 2003 e 2004, no auge da construção da hidrelétrica, no entanto, em 2006 iniciou a recessão, com maior destaque na cidade de Peixe, que teve um número de demissões alarmantes e demorou a recuperar pelo menos a condição inicial, antes do empreendimento. Isso demonstra claramente uma economia de boom and bust, em curto espalho de tempo. Além do déficit no emprego, é necessário ressaltar que em pequenos municípios, com recursos e oportunidades escassas, uma queda brusca de emprego, geram problemas de toda ordem, tanto sociais como econômicos graves, e viu-se que o município demorou 
na recuperação de pelo menos o patamar inicial.

Nos municípios atingidos pela UHE São Salvador, ocorreu o mesmo movimento observado no período da implementação da UHE Peixe Angical. A geração de emprego tem um pico no auge da construção, mas após a inauguração do empreendimento, os números despencam, com destaque ainda mais para a sede da UHE, que fica em São Salvador. Ou seja, o que seria um benefício ao município que aloja o empreendimento, muitas vezes não se traduz em realidade haja vista que os prejuízos imediatos e o período de recuperação podem não compensar a curto prazo.

Destaca-se que tanto com a UHE de Peixe como a de São Salvador, os municípios sede foram os mais prejudicados, na questão geração de emprego, mesmo saindo da depressão (bust) em média após dois anos do término do empreendimento, volta aos números iniciais de antes do empreendimento, ou seja, não melhora essas variáveis no município, com a operação do empreendimento. O que leva a concluir que na fase de operação, as pessoas do local não ocupam postos de trabalho na UHE. Diante disso, o empreendimento não fez diferença para a geração de renda no local a longo prazo, apenas no momento do boom da construção.
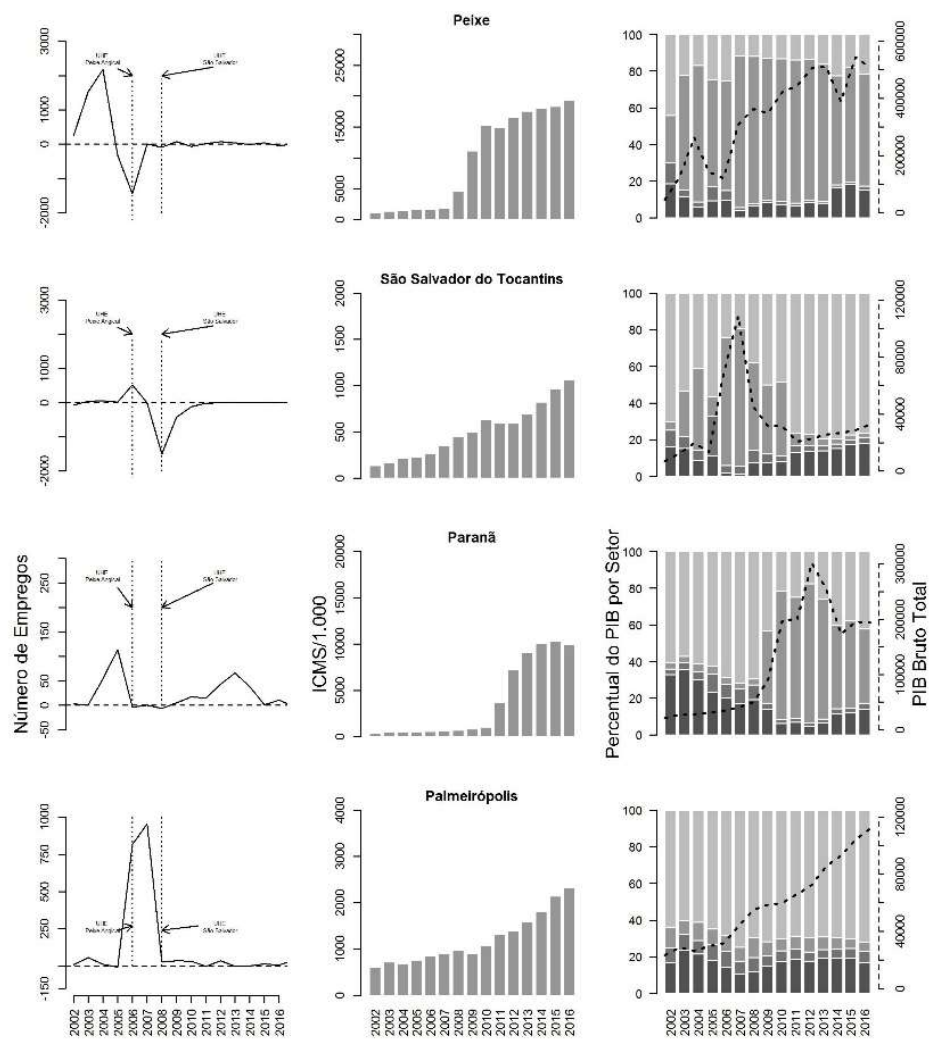

Figura 4: Variação dos Empregos gerados, da arrecadação de ICMS e PIB nos municípios impactados diretamente pela UHE Peixe Angical e São Salvador.

\section{Análise das variáveis econômicas nos municípios tocantinenses impactados pela UHE Estreito}

A hidrelétrica de Estreito, apesar de ter impactado diretamente 10 municípios tocantinenses, nenhum dos analisados é sede do empreendimento, que fica no Estado do Maranhão. Nesse caso, não é possível comparar os municípios diretamente atingidos com aqueles que são a sede do empreendimento como ocorreu em Lajeado, Peixe Angical e São Salvador, mas assim como os outros, apresentam oscilações 
bruscas nas variáveis, especialmente, número de empregos, por estarem diretamente implicados tanto no âmbito econômico como no socioambiental.

Os municípios de Aguiarnópolis e Babaçulândia (fig. 5), tiveram alterações no pico da obra, com contribuições na empregabilidade a partir de 2006 e no auge em 2008, no entanto, a partir de 2010, ano da conclusão do empreendimento, observou-se os sinais de bust, com a queda significativa de postos de trabalho. Interessante ressaltar que Aguiarnópolis é um município que apresenta uma dinâmica de boom and bust em períodos curtos, não só com o empreendimento hidrelétrico, mas se verifica uma outra ocorrência em 2014 e em 2017. Essas variações podem estar relacionadas com a instalação de uma indústria de processamento da soja, que tem a proposta de instalação do parque de esmagamento/processamento da soja e do parque gerador de biodiesel, anunciado sua implementação em etapas para 2013-2014, primeira etapa e 2015-2018, segunda etapa, como observa-se na dinâmica do gráfico de empregos.

Com a variação de atividades, o ICMS manteve-se em constante crescimento, mais acentuado em Aguiarnópolis, mas também observado em Babaçulândia. Já o município de Barra de Ouro (fig. 5) não apresentou alterações significativas quanto a geração de empregos, durante o período de construção da UHE Estreito e, conclui-se que para esse município a implementação da UHE Estreito, não causou alterações no processo de desenvolvimento. O ICMS teve aumento constante, atribuído a outros fatores e atividades no município.

Nos municípios de Darcinópolis e Filadélfia (fig. 5), foi possível identificar a movimentação de boom and bust durante o período de implementação da UHE, como visto em outros municípios, no entanto é perceptível esse movimento em períodos posteriores também. Esses municípios tem uma dinâmica de altos e baixos, na geração de empregos, mas também observado no ICMS, em alguns anos.

Goiatins (fig. 6), apresenta uma geração de emprego após a finalização da construção da hidrelétrica (boom), mas também sofre um bust em 2013/2014, o que é possível que tanto esse boom quanto o bust, não tem relação com a hidrelétrica, mas com outros projetos no município. Durante o período de instalação da UHE, houve poucas alterações quanto aos empregos gerados. O ICMS também sofre altos e baixos, especialmente quando sofre um bust nos empregos (2013/2014) e cai também em 2015. No gráfico do PIB, identifica-se que o setor agropecuário é o mais significativo no município. Itapiratins (fig. 6), teve um pico em 2013, que podem ter sido provocados por outros empreendimentos ou projetos governamentais de incremento agrícola, que vem ocorrendo na região.

Palmeirante (fig. 6), percebeu-se um comportamento inverso aos dos outros municípios, no período do pico da obra, houve significativa queda no saldo de emprego daquele ano. O município foi apresentar melhoria a partir de 2012, um tempo depois do termino da obra e depois se manteve em baixa. De todo modo, para esse município o resultado desse grande empreendimento não trouxe resultados positivos, pois as variáveis, mesmo no pico da obra, que costuma ser um boom, foi a pior recessão do período. Fatores dos impactos ambientais e sociais causados, aliados à governança municipal pode também ter influenciado nesse resultado, além que pode ter havido migração desse município para o município da obra. 

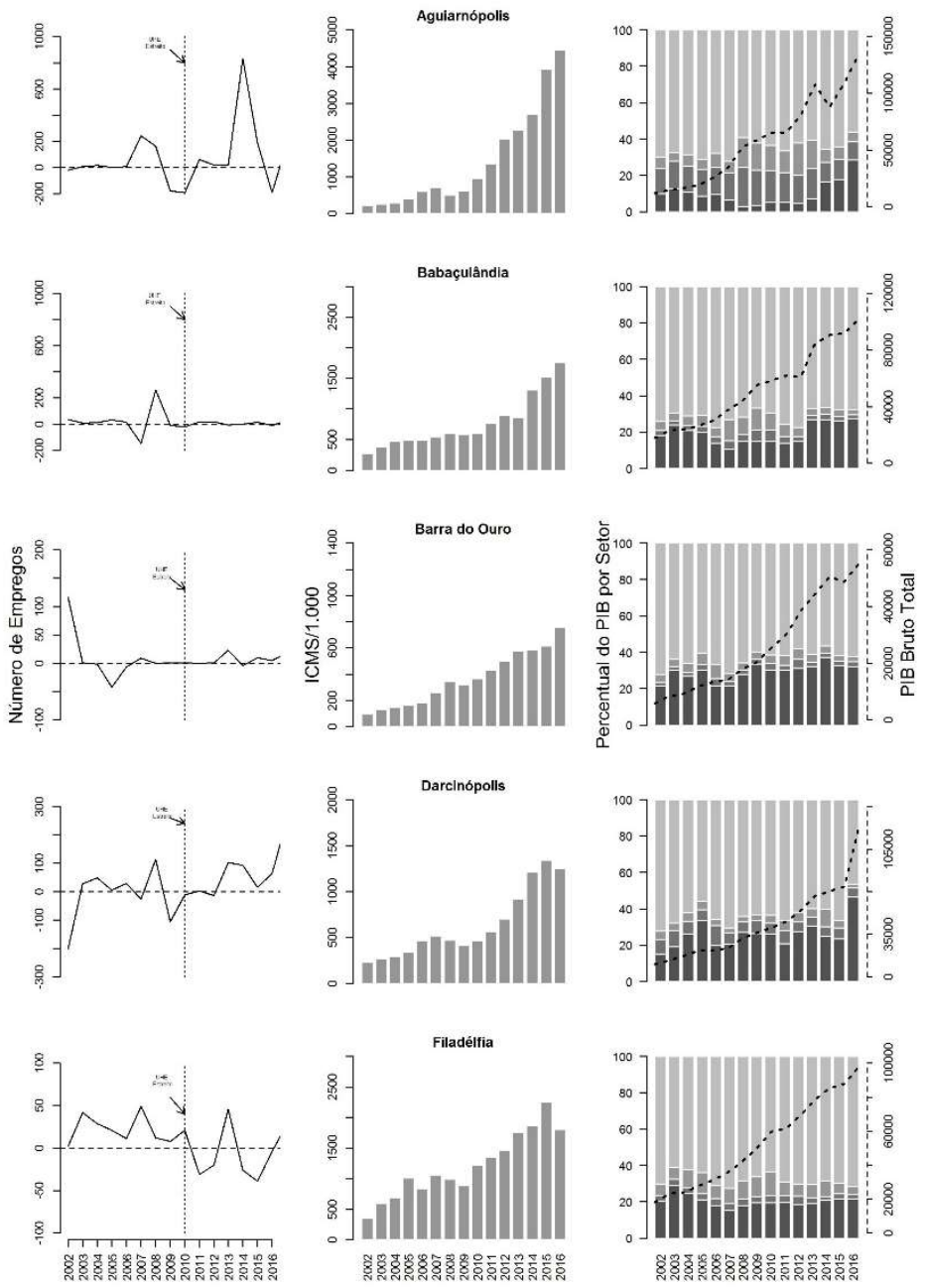

Figura 5: Variação dos Empregos gerados, da arrecadação de ICMS e PIB nos municípios impactados diretamente pela UHE Estreito.

Palmeiras do Tocantins (fig. 6), apresenta vários episódios de colapso, com a geração de emprego na maioria dos períodos analisados. Especificamente, a partir do término da obra, há uma queda brusca nos postos de trabalho, seguido por um período ainda mais crítico em 2012 e depois em 2014. É muito latente que nesse município a UHE Estreito não ocasionou benefícios nesse setor, conforme anunciado. O ICMS obteve-se dentro de um crescimento constante. Tupiratins (fig. 6) apresentou melhoria significativa na geração de empregos em 2007, no entanto já começa a decrescer em 2008, que depois tem alguns picos de melhora, no entanto de um modo geral, esse município não consegue dados positivos de emprego até os dias atuais.

Após analisado a variável de geração de empregos nos municípios atingidos pelas UHEs, percebe-se que a melhoria de emprego e renda propagada pelas obras desenvolvimentistas, no contexto das hidrelétricas, não trazem os benefícios prometidos. Alguns casos, de municípios que sediam o empreendimento, que deveriam ter essa continuidade de emprego na fase de geração, percebe-se que os são ainda mais alarmantes, com o bust após a construção e retorna a situação inicial como é o caso de Peixe e São Salvador. O que podemos refletir que, quanto a geração de emprego na cidade não alcança efeitos positivos significativos. 

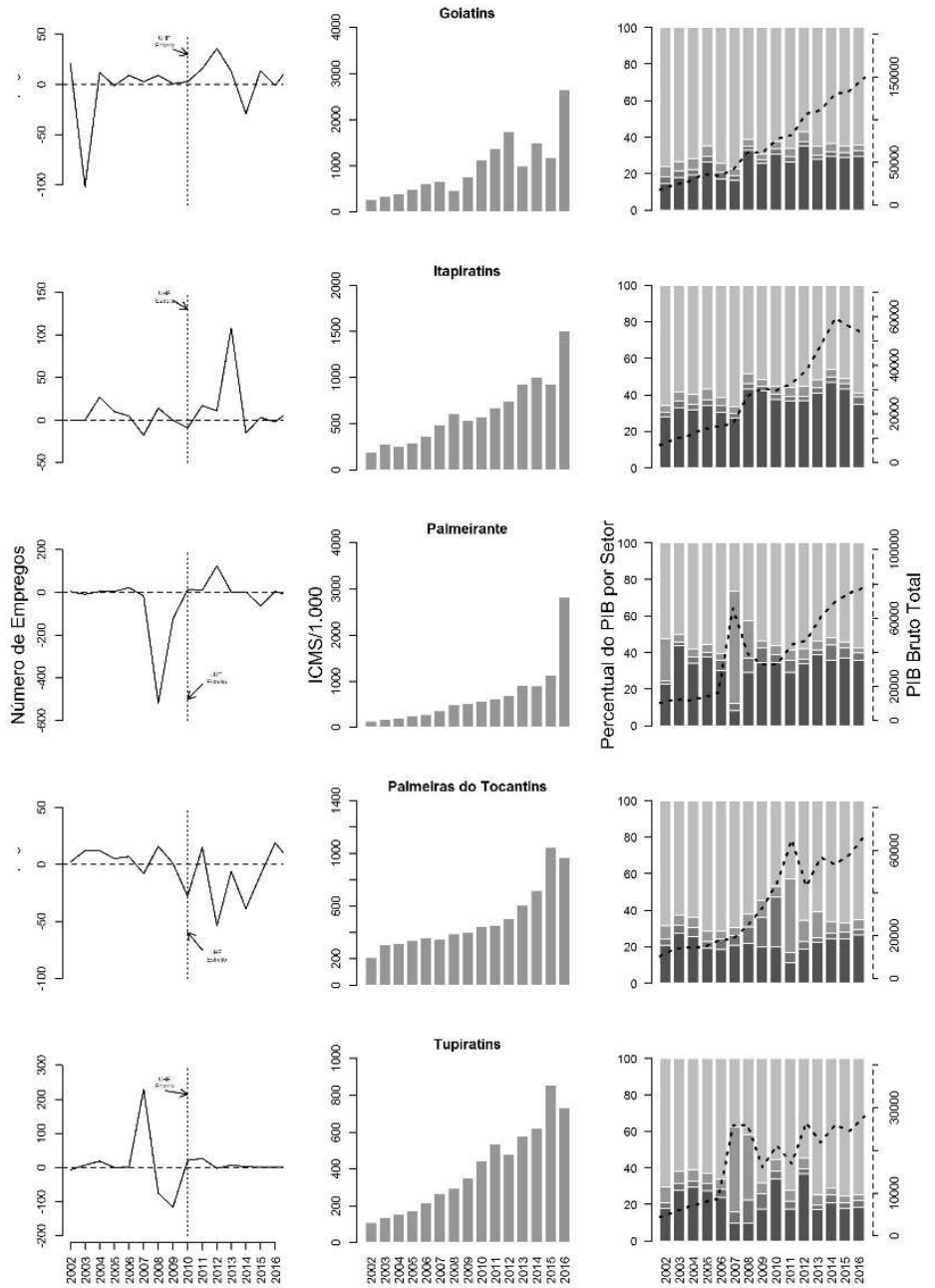

Figura 6: Variação dos Empregos gerados, da arrecadação de ICMS e PIB nos municípios impactados diretamente pela UHE Estreito.

Observa-se ainda que no PIB decomposto nesses municípios estudados, seguem a mesma tendência de boom and bust, durante o período de implementação das obras hidrelétricas, assim como todo grande projeto desenvolvimentistas, geram emprego e serviços (boom), que se traduz numa imagem de 'desenvolvimento', mas induzido e temporário. Identifica-se pelos gráficos do PIB esse crescimento, no setor de serviços, notoriamente no período de construção das UHEs, e em alguns casos em outro período causado por algum outro novo empreendimento, no entanto, com o mesmo comportamento temporário, depois de implementada a obra, O PIB varia de serviços para outras áreas.

Na maioria dos casos estudados, sua tendência regional de crescimento, que está quase sempre voltado ao setor agropecuário volta a se destacar após a implementação da hidrelétrica. Essa percepção só é possível quando analisamos o PIB decomposto e em períodos menores do que as estatísticas do censo. Por fim, foi possível identificar que o período de licenciamento está diretamente ligado com a movimentação nos municípios. A partir da licença de instalação, a propagação toma uma proporção maior, já que existe expectativas de valorização fundiária, geração de emprego, circulação financeira, oportunidade para novos empreendimentos, dentre outros. Dessa forma, atrai muitas pessoas em busca de trabalho e pequenos investidores para negócios locais. O processo se repete em quase todas as localidades. No entanto, os 
resultados não são tão expressivos, exclusivamente por um projeto.

Assunção et al. (2016), em estudo voltado aos efeitos locais de hidrelétricas no Brasil, corroboram que quase sempre, a economia local do município é afetada positivamente somente em curto prazo, aquele período que chamamos de boom, no entanto, após cinco anos do início da construção da UHE, não se encontram efeitos efetivos na taxa de crescimento do PIB municipal, no PIB per capita, no número de empresas localizadas no município, e nem na população do município, que geralmente tem uma baixa significativa com o desmonte da obra.

\section{CONCLUSÕES}

Retomando a questão norteadora desse trabalho, em relação a atribuir desenvolvimento local por meio do aumento das variáveis econômicas para os municípios em decorrência da implementação de grandes projetos de infraestrutura, focando nas hidrelétricas do Tocantins, não é possível atribuir desenvolvimento em decorrência exclusivamente desses projetos. Confirmou-se o movimento de boom and bust, nos períodos de implementação e término da obra respectivamente.

Não foi possível atribuir que empreendimentos hidrelétricos proporcionam desenvolvimento local, ainda que se identifique melhoria de variáveis econômicas, a exemplo o aumento do ICMS, porque fatores como outros investimentos, gestão municipal e negociação com empreendedores, podem interferir para diferentes resultados para municípios impactados pelo mesmo empreendimento.

A estratégia de desenvolvimento local deve ser considerada caso a caso, uma vez que as necessidades e demandas das localidades e territórios são diferentes, as capacidades dos habitantes, empresas e comunidade local mudam e, além disso, cada comunidade pode ter uma visão diferente das prioridades que devem incorporar as políticas de desenvolvimento para a sua localidade (VAZQUEZ-BARQUERO, 2009).

De uma forma ou de outra, sem a participação da sociedade, qualquer plano de desenvolvimento, pode ter comprometimento de seus resultados, pois mesmo que haja uma grande impulsão de recursos, ocasionada por uma política nacional, é necessário envolvimento da gestão local e comunidade para a continuidade e manutenção.

Os impactos causados por grandes obras ocasionam de fato um fenômeno de boom and bust, e exige da gestão municipal medidas que possam sanar problemas no período pós- barragem, quando deveria ter políticas de incremento para dar continuidade ao crescimento econômico local. Portanto, há de se pensar na forma como esses empreendimentos são planejados, visto que, os municípios que possuem hidrelétricas em muitos casos, apresentam uma tendência de crescimento, ligado a outros setores (como visto no PIB), não sendo contabilizados créditos de melhoria no desenvolvimento local devido a esses empreendimentos como propagados inicialmente. Os problemas socias, ambientais e econômicos tendem a ser evidenciados principalmente depois da fase de construção, comprometendo a governança municipal, que ao se deparar com tantos problemas, questionam que tal empreendimento não trouxeram o desenvolvimento local almejado. 


\section{REFERÊNCIAS}

ANEEL. Agencia Nacional de Energia Eletrica. Relatório ANEEL 10 anos. Brasília: ANEEL, 2008.

ASSUNÇÃO, J.; SZERMAN, D.; COSTA, F.. Estudo: Efeitos locais de hidrelétricas no Brasil. INPUT. Climate Policy Iniciative. 2016.

BENINCÁ, D.. Energia \& cidadania: a luta dos atingidos por barragens. São Paulo: Cortez, 2011.

BERMANN, C.. O Setor Elétrico Brasileiro e a

Sustentabilidade no Século 21: Cenário atual. In: MOREIRA, P. F.. O Setor Elétrico Brasileiro e a Sustentabilidade no Século 21: Oportunidade e Desafios. Brasília: Rios Internacionais, 2012.

BERTELLI, A. M.. Formação de Bolhas e a Eclosão da Crise Financeira de $\mathbf{2 0 0 8}$ Sob A Perspectiva Econômica Austríaca. Monografia (Graduação) - Faculdade de Economia e Administração, São Paulo, 2011.

BRASIL. Ministério de Minas e Energia, Empresa de Pesquisa Energética. Plano Decenal de Expansão de Energia 2021. Brasília: MME/EPE,2012.

CELENTANO, D; VERISSIMO, A.. O avanço da fronteira na Amazônia: do boom ao colapso. Belém: Instituto do Homem e Meio Ambiente da Amazônia, 2007.

CNEC. Campanha Nacional de Escolas da Comunidade. Estudos de viabilidade da UHE Estreito. CNEC, 2001.

\section{DIEGUES, A. C.. Desmatamento e modos de vida na} Amazônia. São Paulo: USP, 2005.

FENZL, N.; COELHO, M. C. N.; SIMONIAN, L.. A Evolução do Setor Energético e o Desenvolvimento Sócio-econômico nos Estados da Amazônia. In: Estados e Políticas Públicas na Amazônia. Belém, 2000. p.245-286.

FEARNSIDE, P. M.. Belo Monte: Actors and arguments controversial Amazonian dam. DIE ERDE: Journal of the geographical Society of Berlim, v.148, n.1, p.14-26, 2017.

GARCIA, M. F.; LIMONAD, E.. Grandes Projetos Hidrelétricos e Desenvolvimento Regional. In: ENCONTRO NACIONAL DA
ANPPAS, 4. Anais. Brasília, 2008.

GOMES, C. S.. Desempenhos de municípios afetados por usinas hidrelétricas: Um estudo de 4 usinas nos rios Pelotas, Canoas e Uruguai. 2014. Tese (Doutorado em Ciências da Engenharia Ambiental) - Universidade de São Paulo, São Carlos, 2014.

HARRIS, L. L.. A teoria austríaca dos ciclos econômicos: seus fundamentos e uma análise da crise de 2008. Monografia de Bacharelado (Faculdade de Economia, Administração, Contabilidade e Atuaria) - Pontifícia Universidade Católica de São Paulo, São Paulo, 2013.

LIMA, A. M. T.. A implantação de usinas hidrelétricas no Tocantins: processo decisório, participação e experiência dos agentes envolvidos. Dissertação (Mestrado em Ciências do Ambiente) - Universidade Federal do Tocantins, Palmas, 2013.

OLIVEIRA, N. M.. Desenvolvimento regional do território do Estado do Tocantins: implicações e alternativas. Tese (Doutorado em Desenvolvimento Regional e Agronegócio) Universidade Estadual do Oeste do Paraná, Toledo, 2015.

OLIVEIRA, S. O.. Desenvolvimento local e organização sócioespacial. Interações: Revista Internacional de Desenvolvimento Local, v.4, n.6, p.47-53, 2003.

ROTHMAN, F. D.. Vidas alagadas: Conflitos socioambientais, licenciamento e barragens. Viçosa: UFV, 2008.

SCHENEIDER, R. R.; ARIMA, E.; VERÍSSIMO, A.; BARRETO, P.; SOUZA JUNIOR, C.. Amazônia Sustentável: limitantes e oportunidades para o desenvolvimento rural. Brasília: Banco Mundial; Belém: Imazon, 2000.

VAZQUEZ-BARQUERO, A.. Desarrollo Local: Una estrategia para tiempos de crisis. Conceptos criticos. Universitas Forum, v.1, n.2, 2009.

SOUZA, A. N.; JACOBI, P. R.. Expansão da matriz hidrelétrica brasileira: uma análise apartir da economia dos bens e serviços públicos. Novos Cadernos NAEA, v.8, n.2, p.35-49, 2015.

A CBPC - Companhia Brasileira de Produção Científica (CNPJ: 11.221.422/0001-03) detém os direitos materiais desta publicação. Os direitos referem-se à publicação do trabalho em qualquer parte do mundo, incluindo os direitos às renovações, expansões e disseminações da contribuição, bem como outros direitos subsidiários. Todos os trabalhos publicados eletronicamente poderão posteriormente ser publicados em coletâneas impressas sob coordenação da Sustenere Publishing, da Companhia Brasileira de Produção Científica e seus parceiros autorizados. Os (as) autores (as) preservam os direitos autorais, mas não têm permissão para a publicação da contribuição em outro meio, impresso ou digital, em português ou em tradução. 